\title{
Descrição dos seruiços de psicologia em delegacias especializadas de atendimento às mulheres no Brasil
}

\author{
Description of Psychological Services at Police Stations Specialized \\ in Assisting Women in Brazil \\ Descripción de los servicios de psicología en delegaciones especializadas \\ de atención a las mujeres en Brasil
}

\author{
Tatiana Machiavelli Carmo Souza* \\ Jaqueline Sanchez de Faria** \\ Universidade Federal de Goiás-Regional Jataí
}

Doi: http://dx.doi.org/10.12804/revistas.urosario.edu.co/apl/a.3687

\begin{abstract}
Resumo
Este estudo buscou caracterizar a atuação de psicólogos em Delegacias Especializadas de Atendimento às Mulheres (DEAMs), no Brasil, objetivando identificar o perfil profissional, as bases epistemológicas, os modelos teóricos e os instrumentos utilizados no cotidiano, bem como os desafios, dificuldades e/ou potencialidades experienciados pelos profissionais no trabalho junto a sujeitos em contexto de violência. A amostra compreendeu 11 participantes, representativos das cinco regiões geográficas brasileiras. A obtenção dos dados deu-se mediante formulário online, disponibilizado via ferramenta Google Doc's e encaminhado por e-mail. As informações constituíram categorias para análise quantitativo-qualitativa. Averiguou-se prática profissional bastante diversificada, apontando que o papel
\end{abstract}

do psicólogo não se limita somente ao espaço físico da delegacia, mas tangencia outras esferas da sociedade. A prática psicológica nas Delegacias da Mulher revelou-se em desafio diário e árdua tarefa para os profissionais, exigindo vasto conhecimento teórico-técnico e disponibilidade afetiva por se tratar de temática de ampla complexidade. A escassez de diretrizes para a atuação, somada à pouca formação profissional, contribui para a existência de dificuldades no enfrentamento da violência contra a mulher.

Palavras-chave: gênero; violência contra a mulher; psicologia.

\section{fibstract}

This study sought to characterize the performance of psychologists at police stations that provide speciali-

\footnotetext{
* Professora do Curso de Psicologia e do Programa de Pós-graduação em Psicologia da Universidade Federal de Goiás. Rua Dona Esmeralda, 1176. Setor Hermosa. Jataí. Goiás. Brasil. CEP 75803-303. Correio electrônico: tatimachiavelli@yahoo.com.br

** Psicóloga na Secretaria de Promocão e Assistência Social da Prefeitura Municipal de Jataí-GO. Rua Napoleão Laureano, 556. Setor Aeroporto. Jataí. Goiás. Brasil. CEP 75805-065. Correio electrônico: jaqueline_sanchez03@hotmail.com
}

Cómo citar este artículo: Souza, T. M. C., \& De Faria J. S. (2017). Descrição dos serviços de psicologia em delegacias especializadas de atendimento às mulheres no Brasil. Avances en Psicología Latinoamericana, 35(2), 253-265. doi: http://dx.doi.org/10.12804/revistas.urosario.edu.co/apl/a.3687 
zed assistance to women (DEAMs) in Brazil, aiming at identifying the professional profile, the epistemological bases, theoretical models and the instruments used on a daily basis, as well as the challenges, difficulties and / or potentials experienced by professionals at work involving individuals surrounded by a violent environment. The sample involved eleven participants, representatives of the five Brazilian geographic regions. The data was obtained through an online form, available in a Google Doc and sent by email. The information consisted of categories for quantitative-qualitative analysis. It was found that there is a diversified professional practice, pointing out that the role of the psychologist is not limited to the physical space of the police station, but also touches other spheres of the society. The psychological practice at Women's Police Stations acknowledged it to be a daily challenge and a tenacious task for the professionals, demanding vast theoretical and technical knowledge and affective availability because it has proven to be a matter of high complexity. The scarcity of guidelines for action, coupled with poor professional training, contributes to the existence of difficulties in coping with violence against women.

Keywords: gender; violence against women; psychology.

\section{Resumen}

Este estudio busca caracterizar la actuación de psicólogos en Comisarías Especializadas para Atender a las Mujeres (CEAM), en el Brasil. Tiene como objetivo identificar el perfil profesional, las bases epistemológicas, los modelos teóricos y los instrumentos utilizados día a día, así como los desafíos, dificultades y/o potencialidades vividas por los profesionales en el trabajo, junto a los sujetos en un contexto de violencia. La muestra comprendió de 11 participantes, representantes de las cinco regiones geográficas brasileñas. La recolección de los datos fue por medio de un formulario online, que está disponible vía Google Doc's y enviado por e-mail. Las informaciones fueron constituidas en categorías para análisis cuantitativo-cualitativo. Se verificó que la práctica profesional es muy diversa, indicando que el papel del psicólogo no se limita solamente al espacio físico de la comisaría, sino que también atraviesa a otras esferas de la sociedad. La práctica psicológica en las comisarías de la mujer reveló un desafío diario y una tarea ardua para los profesionales, exigiendo un vasto conocimiento teórico-técnico y disponibilidad afectiva por tratarse de un tema complejo. La escasez de directrices para la actuación, sumada a la poca formación profesional, contribuye para la existencia de dificultades en el enfrentamiento de la violencia contra la mujer. Palabras clave: género; violencia contra la mujer; psicología.

\section{Introdução}

Esse trabalho trata-se de fruto do projeto de extensão intitulado "DEAM: práticas psicossociais em contexto de violência”, realizado em parceria entre o curso de Psicologia da Universidade Federal de Goiás/Regional Jataí e a Delegacia Especializada de Atendimento à Mulher (DEAM) deste município. Partindo dessa experiência, buscou-se investigar a realidade profissional dos psicólogos em delegacias, no intuito de caracterizar as práticas adotadas frente ao atendimento de mulheres em contexto de violência.

\section{Violência e gênero}

O interesse acadêmico sobre o tema da violência contra a mulher, no Brasil de modo específico, remete ao início da década de 1980 (Santos \& Izumino, 2005). Trata-se de produto de transformações sociais e políticas ocorridas no país, que acompanharam o desenvolvimento dos movimentos sociais ligados às causas feministas, assim como do processo de redemocratização. Nesse momento histórico, buscava-se dar visibilidade à violência acometida contra as mulheres no intuito de combatê-la, empregando, para tanto, medidas de caráter social, psicológico e jurídico. A criação das delegacias da mulher foi uma das primeiras conquistas desta época, instituindo-se como 
referencial de política pública para enfrentamento dessa demanda (Brasil, 2005, 2011).

O estudo da temática implica na discussão sobre as questões relacionadas ao gênero, entendido como construção cultural coletiva das características pertencentes ao que é reconhecido como masculino ou feminino (CREPOP, 2011; Brasil, 2011). Percebe-se que, historicamente, essas relações foram estabelecidas a partir de padrões comportamentais e modelos do que é considerado como pertencente ao masculino e ao feminino, na sociedade. Tais padrões nasceram nas tramas das relações hierárquicas e patriarcais, nas quais homens e mulheres relacionavam-se de maneiras distintas, reforçando a ideia de dominação e poder de um sobre o outro (Parada, 2009; Saffioti, 2001).

No que tange à realidade brasileira, a figura da mulher constituiu-se no papel de subordinação ao masculino, colaborando para a condição de privilégio, prestígio e poder do homem; apreende-se que esta suposta relação de inferioridade feminina também é resultante de uma construção cultural. Em outras palavras, a mulher introjetou aquilo que lhe foi transmitido culturalmente, acreditando na superioridade do homem bem como no dever de subordinar-se a ele (Saffioti, 2001; Santana, 2010). Desta forma, a violência acometida contra as mulheres é tida não como fruto das diferenças biológicas existentes entre os sexos, mas é um instrumento ao qual o homem recorre para manter a dominação.

Verificam-se, no Brasil, alguns movimentos e documentos que contribuíram para o enfrentamento da violência, como o Movimento Feminista, nas décadas de 1970 e 1980 (Saffiotti, 2001), a Declaração sobre a Violência Contra a Mulher, aprovada na Conferência de Viena, em 1993 (Adeodato, Carvalho, Siqueira \& Souza, 2005); a Convenção Interamericana para Prevenir, Punir e Erradicar a Violência Contra a Mulher, conhecida como "Convenção Belém do Pará" (Brasil, 1994). Dentre esses, destaca-se a Lei nº11. 340 (Brasil, 2006), popularizada como "Lei Maria da Penha", consi- derada marco na proteção dos direitos humanos das mulheres.

A Lei Maria da Penha apresenta avanços ao estabelecer medidas relacionadas à assistência, proteção, punição e reeducação dos agressores. Prevê a articulação entre União, Estados, Distrito Federal, municípios e de ações não governamentais com a finalidade de desenvolver medidas integradas de prevenção. Ademais, aponta ações afetas à instituição policial como deflagrar prisão preventiva ao agressor no caso de descumprimento de medidas protetivas destinadas a vítimas de violência; autuar prisão em flagrante ao agressor; conceder medidas de proteção até dois dias após o registro da queixa, por decisão judicial; efetuar prisão preventiva dos agressores; práticas essas que não poderiam ser executadas anteriormente à existência da lei.

\section{Psicólogo na DEAM}

A fundação da primeira DEAM, no Brasil, data do ano de 1985, na cidade de São Paulo. Foi criada como instrumento para lidar com a violência perpetrada contra a mulher e considerada experiência inicial da implementação de políticas públicas voltadas ao combate e enfrentamento dessa realidade, oferecendo serviços de caráter preventivo e repressivo, como ações de apuração, investigação e enquadramento legal, garantindo os direitos humanos e os princípios do Estado Democrático de Direito (Brasil, 2010).

A importância do serviço desempenhado pelas delegacias da mulher reside na consolidação de espaço e atendimento diferenciados, permitindo às mulheres o acolhimento para suas queixas e denúncias. Atualmente, há mais de 300 instituições distribuídas pelos estados brasileiros que atendem mulheres vítimas de violência, entretanto, recebem, de acordo com a localidade, nomenclaturas diferenciadas, tais como Delegacia de Defesa da Mulher (DDM), Delegacia para a Mulher (DM) e 
Delegacia Especializada de Atendimento à Mulher (DEAM) (Gadoni-Costa, Zucatti \& Dell'aglio, 2011).

A complexidade da temática envolvendo mulheres em situação de violência abrange aspectos como os de ordem social, econômico, étnico, psicológico, entre outros. Deste modo, cabe aos profissionais que atuam nas DEAMs propiciar assistência humanizada, pois se trata de mulheres que se encontram com sua integridade física e psicológica abaladas, e, usualmente, com o agravante da violação dos seus direitos humanos (Brasil, 2010).

A inserção de psicólogos nas DEAMs ainda constitui-se em grande desafio, já que a atuação profissional tangencia variadas atividades, desde a identificação dos sinais de violência, a avaliação das condições psicossociais em que a violência é efetivada, até o desenvolvimento de ações para a superação da violência (CREPOP, 2011). Entende-se, portanto, que o papel do psicólogo nesse contexto está intimamente relacionado a propiciar o acolhimento das mulheres por meio de olhar diferenciado, isto é, não deixando com que o estereótipo de "vítima" se sobreponha aos direitos de ser humano. Dessa forma, o psicólogo necessita promover reflexões acerca da situação vivenciada, auxiliando a mulher na escolha de novos caminhos e possibilitando a ressignificação de experiências.

\section{Método}

Trata-se de pesquisa quantitativa-qualitativa, com aprovação do Comitê de Ética em Pesquisa da Universidade Federal de Goiás (COEP/UFG), sob o parecer $\mathrm{n}^{0}$ 334.416. A amostra foi formada por conveniência. Como critério de inclusão, foram selecionados profissionais graduados em Psicologia, que atuaram em delegacias de atendimento à mulher no Brasil. Como critério de exclusão, não foram elegidos estagiários e estudantes que desenvolviam intervenções por meio de projetos de extensão e/ou atividades vinculadas à graduação em Psicologia.
Para a composição da amostra, realizou-se busca via internet e via solicitação ao Conselho Federal de Psicologia (CFP), com o intuito de localizar as delegacias da mulher distribuídas pelo Brasil que contavam com alguma modalidade de serviço de Psicologia. Dada a escassez de informações públicas sobre tal realidade, optou-se por fazer contato, inicialmente com as DEAMs alocadas nas 26 capitais e Distrito Federal e, de modo secundário, com aquelas situadas no interior. Foi possível contatar 72 DEAMs. Verificou-se que desse número, 56 não contavam com o trabalho do psicólogo e 4 disponibilizavam os atendimentos por meio de estagiários. Foi solicitada participação dos demais 12 psicólogos, entretanto, 11 responderam o instrumento encaminhado, compondo assim a amostra.

O processo de obtenção de dados foi efetivado, no segundo semestre de 2013, a partir de formulário online. Este foi enviado via internet/e-mail, por meio da ferramenta Google Docs. Antes de responder ao formulário, o sujeito deveria, obrigatoriamente, validar o Termo de Consentimento Livre e Esclarecido. Almejando resguardar a identidade dos sujeitos, no decorrer do estudo, utilizou-se pseudônimo.

O formulário foi elaborado com o intuito de conhecer o cotidiano do psicólogo na DEAM, com destaque às intervenções utilizadas junto a mulheres em contexto de violência, bem como para investigar os desafios, entraves e possibilidades vivenciadas pelos profissionais.

A leitura e interpretação dos dados deram-se por meio da análise de conteúdo, caracterizada como metodologia de pesquisa empregada na descrição e interpretação do conteúdo de toda categoria de documentos e textos. Foram desenvolvidas 5 categorias de análise: (a) caracterização dos sujeitos (sexo, idade, tempo de formação e localização); (b) motivações para a atuação em DEAMs; (c) características da atuação profissional; (d) desafios da prática profissional; (e) papel do psicólogo na DEAM. 


\section{Resultados e Discussão}

\section{Caracterização dos psicólogos: sexo, idade, tempo de formação e localização}

Verificou-se que todos os participantes da pesquisa constituíram-se em sujeitos do sexo feminino. Ressalta-se que no decorrer do processo de obtenção de dados, obteve-se o conhecimento, por meio de terceiros, de homens/psicólogos que atuavam em DEAMs, entretanto, não foi possível localizá-los.

Em estudos, Lhullier (2013) e Casto e Yamamoto (1998) identificaram forte presença feminina no exercício da Psicologia no Brasil. Cabe destacar que, dos 232 mil profissionais em exercício no período da pesquisa, $88 \%$ eram mulheres, representando, desta forma, a presença majoritária de indivíduos do sexo feminino atuando na área da Psicologia (Lhullier, 2013). Nessa direção, apesar das instituições policiais serem predominantemente marcadas pela presença de homens, averiguou-se que as práticas psicológicas nas DEAMs têm sido efetivadas por mulheres.

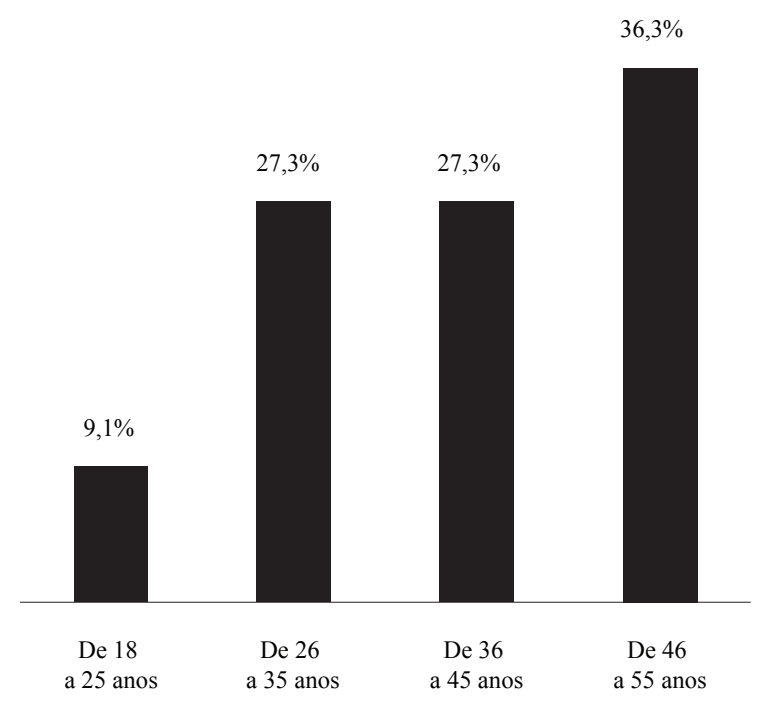

Figura 1. Idade das participantes

No que tange a idade dos sujeitos da pesquisa, observou-se maior concentração na faixa etária entre 46 a 55 anos, o que correspondeu a 36,3\% da amostra. Esta faixa etária poderia indicar acúmulo de experiências pessoais e profissionais. Em contrapartida, quando confrontado com o tempo de formação, a grande parte $(54,5 \%)$ apresentou experiência profissional compreendida entre 1 e 5 anos. Nesse sentido, apesar das participantes serem mulheres adultas de meia idade, percebeu-se que apresentavam tempo de experiência profissional consideravelmente pequeno, pressupondo que são profissionais em começo de carreira ou com pouco repertório profissional no âmbito da Psicologia.

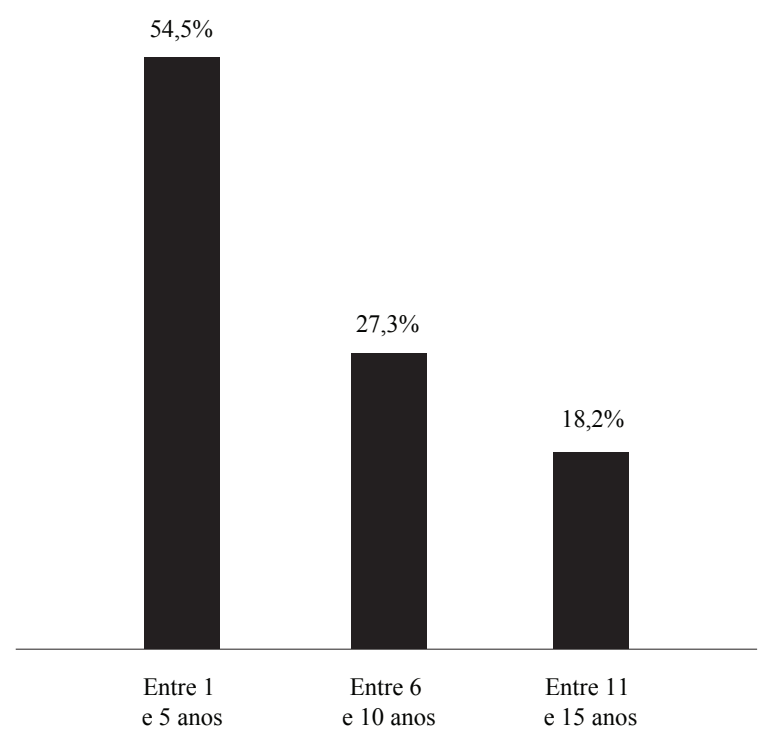

Figura 2. Tempo de formação das participantes

Conforme apontado na metodologia, a amostra foi constituída por participantes das cinco regiões geográficas brasileiras, com maior representatividade na região Sudeste $(36,4 \%)$, seguida pelo Centro-oeste (27,3\%), Sul (18,1\%), Norte e Nordeste $(9,1 \%$ cada). Quanto às localidades em que as participantes estavam alocadas, obtiveram-se os seguintes resultados, divididos quanto aos estados e respectivas cidades: Acre (Rio Branco); Bahia (Salvador); Goiás (Goiânia, Jataí e Rio Verde); São Paulo (São Paulo, Lins e Franca); Minas Gerais (Pará de Minas); e Rio Grande do Sul (Porto Alegre e Novo Hamburgo). 


\section{Motivações para a atuação em DEAMs}

Verificou-se que o interesse e a aproximação das participantes com a temática da violência deram-se a partir de duas dimensões: experiências pessoais e experiências profissionais. Com relação às experiências pessoais, constatou-se que o contato com a temática da violência decorreu de vivências violentas no período da infância, do envolvimento em movimentos e manifestações sociais organizados por mulheres, de trabalhos voluntários e/ ou de relações afetivas com parceiros violentos.

[...] devo dizer que meu contato com violência doméstica, ou mulheres que sofrem violência aconteceu desde a minha infância [...] (Sílvia).

[...] Meu primeiro contato foi comigo mesma. Vivi uma relação de violência doméstica por 10 anos [...] (Michele).

[...] A motivação maior foi porque tenho e tive pessoas da própria família que já vivenciaram e outras ainda estão vivenciando esse fenômeno, inclusive, já tive três casos de morte na família [...] (Juliana).

Destacam-se as experiências pessoais com companheiros violentos e/ou familiares com parceiros violentos que conduziram as participantes a práticas psicológicas em delegacias. De acordo com a pesquisa do CFP (Lhullier, 2013), 27\% das psicólogas entrevistadas já sofreram algum tipo de violência ao longo da vida, tais como agressão verbal (56\%); agressão física (31\%); assédio moral (26\%); assédio sexual (15\%) e violência sexual (11\%). Quanto ao autor da violência, em primeiro lugar, com $22 \%$, estavam parentes ou familiares (com exceção, o cônjuge); $13 \%$ representavam superiores hierárquicos (relações de chefia), e $12 \%$ ex-companheiros, cônjuges, maridos ou namorados. Os dados encontrados reiteram, qualitativamente, a pesquisa do CFP (Lhullier, 2013), isto é, verificou-se o envolvimento direto de profissionais da área da psicologia como vítimas de violência. Embora esse não seja o foco do estudo aqui apresentado, esse dado pode conduzir a alguns questionamentos: o fato da psicóloga já ter sido violentada modifica suas condutas no atendimento de mulheres em contexto de violência? A experiência da violência pessoal pode significar um entrave ou pode proporcionar empatia na experiência profissional?

Por conseguinte, quanto às experiências profissionais, as participantes apontaram a universidade como sendo espaço que permitiu o encontro com a temática da violência de gênero, por meio de diversas atividades acadêmicas, como projetos de extensão, estágios, elaboração da monografia para conclusão do curso de graduação e através de disciplinas vinculadas a área jurídica.

[...] Em meu curso de graduação em Psicologia, desde o segundo ano realizamos estágios. Eu estagiei por 2 anos na Delegacia de Defesa da Mulher [...] (Sílvia).

[...] Tudo começou quando eu fiz minha monografia nesse tema, violência doméstica contra a mulher. Em outubro de 2011 comecei a vivenciar na prática, na própria DEAM [...] (Juliana).

[...] A disciplina de psicologia jurídica. [...] Depois estive no setor da Psicologia da DEAM por quase 5 anos, onde coordenei o setor e assumi a responsabilidade de orientar estagiários da área de Psicologia Jurídica [...] (Maria).

Destaca-se a universidade como importante instituição para a aprendizagem e desenvolvimento de ações acerca da temática da violência. Sabe-se, entretanto, que os estudos de gênero têm sido marginalizados pela psicologia acadêmica contemporânea (Narvaz \& Koller, 2007; Narvaz, 2009), podendo conduzir à compreensão rasa ou difusa da temática. Verificou-se também a existência e o papel de outras instituições como forma de aproximação da temática; em especial, o voluntariado apresentou-se como elemento que instigou as participantes a lidar com a violência. 
[...] No ano de 2005, trabalhei no CRAS e tive a oportunidade, no grupo mensal de mulheres, de ter contato com mulheres em situação de violência. [...] Também trabalhei em unidades de internação para adolescentes infratores, onde parte das mães dos adolescentes encontravam-se em situação de violência ou já tinham vivenciado situações de violência. Além da DEAM, também faço 'atendimento inicial' a adolescentes e crianças vítimas de violência na NUCRIA/Delegacia (Núcleo de Atendimento à Criança e Adolescente Vítima). (Larissa).

[...] Começamos o trabalho como voluntárias e recebemos pelo trabalho depois de um tempo, por ementa parlamentar [...] (Beatriz).

[...] Fizemos um trabalho belíssimo, com muita ética e responsabilidade social. Um belo dia, o governador na época me exonerou da função (eu e outras centenas) e continuei um ano como voluntária porque acreditava o trabalho que fazia e precisava manter aberto aquele campo de estágio [...] (Maria).

Nesse sentido, é possível afirmar que parcela das profissionais começou a trabalhar na delegacia sem prévios conhecimentos teóricos e metodológicos, adquirindo experiências no decorrer da atuação. Nessa direção, destaca-se a lacuna acerca da temática de gênero que a universidade deixa no processo de formação de psicólogos, já que essas problematizações não têm sido feitas pela psicologia acadêmica (Narvaz \& Koller, 2007; Narvaz, 2009). Acredita-se que as discussões sobre as questões de gênero e violência devam ter lugar central, por se tratar de categoria profissional formada, em ampla maioria, por mulheres e por essas temáticas tangenciarem os diferentes campos de atuação da psicologia.

\section{Características da atuação profissional}

Quanto à caracterização da prática profissional na DEAM, observou-se diversidade no que diz respeito à divulgação do serviço junto à comunidade; à modalidade de atendimento; à abordagem teórico-metodológica empregada e às de redes de apoio vinculadas ao acolhimento de mulheres em contexto de violência.

Verificou-se que o atendimento psicológico é disponibilizado de forma gratuita, não obrigatória, ou seja, fica a critério da mulher aceitar ou não; e não implica na obrigatoriedade de efetivação do boletim de ocorrência, assim, há atendimento mesmo quando a denúncia não é formalizada. Em algumas DEAMs, é realizado em caráter imediato e em outras, por meio de agendamentos.

Agentes, policiais, escrivães, oficiais, delegados e recepcionistas, foram os profissionais citados como aqueles que oferecem e divulgam o serviço de psicologia à população que recorre à delegacia. A colaboração destes indivíduos revelou-se em parceria muito interessante, uma vez que a mulher chega ao atendimento psicológico não somente via psicólogo, mas por meio dos funcionários. Observou-se que independentemente da forma como o serviço é disponibilizado, havia preocupação das participantes quanto à tentativa de oferecer o atendimento psicológico à população.

As participantes também assinalaram tentar fortalecer a rede de apoio, buscando parceiras com outras instituições, como o Centro de Referência de Assistência Social (CRAS), os abrigos, o Centro de Referência Especializado de Atendimento Social (CREAS), Organizações Não Governamentais e outras instituições que lidam com questões de violência, já que os serviços oferecidos pelas DEAMs são precários ou insuficientes frente às demandas.

Quanto aos modelos de intervenção, cada participante apontou mais de uma opção para a prática profissional. Encontrou-se prevalência da utilização do acolhimento psicológico $(23,9 \%)$ e da psicoterapia breve $(17,4 \%)$ como intervenções adotadas no cotidiano de trabalho.

No que tange às teorias e/ou correntes filosóficas que fundamentam o trabalho psicológico, 
Tabela 1

Modelos de intervenção psicológica verificados no contexto da DEAM

\begin{tabular}{lcc}
\hline \multicolumn{1}{c}{ Modelo de intervenção } & Freqüência & Porcentagem \\
\hline Plantão psicológico & 4 & 8,7 \\
Triagem & 5 & 10,9 \\
Acolhimento Psicológico. & 11 & 23,9 \\
Psicoterapia Beve & 8 & 17,4 \\
Anamnese & 5 & 10,9 \\
Entrevista & 6 & 13,0 \\
Grupos Terapêuticos & 3 & 6,5 \\
Testes Psicológicos & 4 & 8,7 \\
\hline Total & 46 & 100 \\
\hline
\end{tabular}

constatou-se que grande parte $(72,7 \%)$ utilizava uma única abordagem para embasar sua prática profissional. Verificou-se que em primeiro lugar, as participantes recorrem à Psicanálise $(45,5 \%)$; em segundo (27,3\%) fazem uso de ecletismo; em terceiro a abordagem Cognitivo-Comportamental (18,1\%); e em último o Psicodrama $(9,1 \%)$. Com relação ao ecletismo - aqui entendido como a junção ou utilização simultânea de dois ou mais sistemas de pensamento teórico-filosófico-observou-se a fundamentação teórico-metodológica utilizada pelos sujeitos em abordagens divergentes, como Psicologia Sócio-Histórica, Psicanálise e Análise do Comportamento, empregadas simultaneamente.

Partindo da concepção de que nenhum campo do conhecimento é neutro, alguns discursos psicológicos, notadamente os baseados em pressupostos biologicistas, higienistas e disciplinadores, apreendem uma visão de ser humano universal, atemporal e a-histórico e marginalizam as questões de gênero (Nardaz, 2009). Ademais, Porto (2013), em pesquisa com grupo de psicólogas, constatou que as teorias psicológicas utilizadas não se mostram adequadas ao atendimento de mulheres em situação de violência, por psicologizarem questões que são sociais e culturais.
Tabela 2

Abordagens teórico-metodológicas utilizadas pelos sujeitos da pesquisa

\begin{tabular}{lcc}
\hline $\begin{array}{l}\text { Abordagenas } \\
\text { teórico-metodológicas }\end{array}$ & Freqüiência(F) & Porcentagem \\
\hline Psicodrama & 1 & 9,1 \\
Psicanálise & 5 & 45,5 \\
$\begin{array}{l}\text { Cognitivo- } \\
\text { Comportamental }\end{array}$ & 2 & 18,1 \\
Ecléctico & 3 & 27,3 \\
\hline Total & 11 & 100 \\
\hline
\end{tabular}

Infere-se que a escassez de diretrizes para a atuação do psicólogo pode conduzir à diversidade de práticas, priorizando perspectivas clínico-médicas na Psicologia. Por conseguinte, a heterogeneidade de teorias empregadas como ecletismo pode indicar fragilidade teórica do profissional frente a esta demanda atendida. Nessa direção, Porto (2013), em estudo sobre a avaliação das orientações propostas pela Secretaria de Política para as Mulheres da Presidência da República, presentes em diversos documentos, para o atendimento psicológico às mulheres em situação de violência, verificou que estas são imprecisas e o papel do psicólogo revela-se ambíguo e contraditório.

\section{Desafios das práticas profissionais}

As dificuldades apontadas pelas participantes quanto ao atendimento às mulheres em contexto de violência na delegacia representaram aspectos referentes à: 1) infraestrutura; 2) baixa adesão do público alvo; e 3 ) configuração do sistema judiciário brasileiro. A prática psicológica na delegacia revelou-se em desafio diário e árdua tarefa para as participantes, exigindo vasto conhecimento teórico-técnico e disponibilidade afetiva por se tratar de temática de ampla complexidade e grande desgaste emocional.

Com relação à infraestrutura disponibilizada para o trabalho do psicólogo, verificou-se que 
$72,7 \%$ das participantes apontaram como sendo o fator que dificulta a realização dos atendimentos, visto que não se tem aparato minimamente necessário para a garantia da qualidade, do sigilo e da preservação da identidade da população atendida. As participantes apontaram utilizar o refeitório e/ ou sala de espera para efetuar os atendimentos. De acordo com Villela, Vianna, Lima, Sala, Vieira, Vieira e Oliveira (2011), a ausência de espaço físico adequado limita a privacidade, dificultando a abordagem de experiências sensíveis; ademais, pode comprometer o acolhimento, tornando impessoal a relação entre o profissional e a mulher atendida.

A baixa adesão do público alvo representou outra dificuldade apontada pelas participantes, visto que ofertar o serviço psicológico não é sinônimo de procura pelo atendimento. Somada a essa questão, verificou-se que as mulheres atendidas tendem a apresentar expectativas com relação ao atendimento psicológico, que muitas vezes não condizem com a prática profissional desenvolvida. Os discursos das participantes apontam, ainda, que as mulheres em contexto de violência recorrem ao psicólogo almejando maior punição do agressor em detrimento do cuidado de si próprias. Estudos como o de Kiss, Schraiber e D'Oliveira (2007), demonstram que a morosidade dos serviços ofertados às mulheres em situação de violência é fator apontado como inibidor da adesão, já que muitas procuram resolução de curto prazo para seus conflitos.

A configuração do sistema judiciário brasileiro foi outro quesito que despertou atenção. A inexistência do cargo de psicólogo alocado nas delegacias, realidade da maioria dos estados do país, bem como a falta de efetividade da Lei Maria da Penha e a complexidade da dinâmica do aparato judiciário foram elencados como elementos que comprometem a atuação do psicólogo.

Quanto às facilidades, as participantes assinalaram questões relacionadas à: (1) atendimento voltado somente às mulheres em contexto de violência, em virtude da especificidade das DEAMs; (2) recursos teóricos e metodológicos adequados à demanda atendida, contemplando de maneira significativa a população que utiliza o serviço da Psicologia; (3) boa aceitação do trabalho da Psicologia por parte dos demais profissionais da DEAM, apontando o reconhecimento dos pares e a visibilidade da categoria profissional. No que diz respeito à segunda questão, é importante problematizar o ponto de vista das participantes. Embora tenham sinalizado que o referencial teórico-metodológico que embasa as ações profissionais no cotidiano da delegacia seja "suficiente", pode-se realizar questionamentos, já que verificou-se a presença de ecletismo, conforme apontado anteriormente.

\section{Papel do psicólogo na DEAM}

Problematizar o papel do psicólogo é tarefa desafiadora. Não há dados nacionais sobre o número de profissionais não policiais atuando nas DEAMS, conforme destacam Pasinato e Santos (2008). A inserção dos psicólogos nas delegacias tem ocorrido por meio da realização de convênios e acordos com os governos municipais e as universidades. Essas parcerias, saída encontrada por algumas secretarias de segurança pública, se efetiva a partir de acordos temporários e a presença do psicólogo na delegacia torna-se descontinuada (Pasinato \& Santos, 2008).

Observou-se que o papel do psicólogo é apreendido pelas participantes de maneira heterogênea, desempenhando funções quanto à: (1) acolhimento psicológico às mulheres que procuram pelo serviço; (2) orientações e/ou informações à demanda atendida acerca da violência doméstica; (3) encaminhamentos a outros serviços da rede de enfrentamento à violência contra a mulher; (4) atuação com responsabilidade social, sendo mediador de transformações sociais; (5) reconhecimento da categoria profissional neste campo de atuação. 
O acolhimento e a orientação às mulheres em situação de violência foram assinalados veementemente pelas participantes, sendo apontados como tarefas impreteríveis. Os encaminhamentos foram apontados como forma de lidar com as limitações institucionais da DEAM e como modo de ampliação das redes de apoio. Pesquisa desenvolvida por Balbueno (2011) aponta que para os profissionais entrevistados, o ideal seria que toda mulher que apresentasse denúncia em uma DEAM pudesse ser atendida por psicólogo de modo emergencial e encaminhada para outras entidades.

[...] acolher, propiciar uma intervenção imediata, no momento em que as pessoas necessitam de acolhimento, prestando atendimento e esclarecimentos sobre seu estado de sofrimento, dificuldades e angústias; ajudar a estabelecer com maior clareza o pedido de ajuda; encaminhar usuárias a outros serviços de rede, como atendimento social, jurídico, psicoterápico [...] (Larissa).

[...] No primeiro momento o papel é de acolhimento e depois o encaminhamento para a área onde for necessário, como por exemplo, o exame de corpo de delito [...] (Michele).

Atuar com ética e comprometimento social, tornando-se agente de transformação na sociedade e buscando formas para reduzir a violência doméstica também foi tarefa elencada como responsabilidade das participantes.

[...] O atendimento psicológico tem como objetivo fundamental a tentativa de interromper a repetição da violência. Para que isso seja possível, acredito que é necessário despertarmos na vítima que existe uma saída, que depende dela desejar sair dessa situação e que podemos ajudar [...] (Isabela).

[...] Na psicoterapia, trabalho a valorização da própria mulher para que ela possa perceber que o que está vivenciando, às vezes, por muitos anos, é um círculo vicioso da violência [...] (Juliana).

[...] contribuir na reflexão acerca das relações interpessoais/conjugais/amorosas em que essas mulheres estão inseridas, dar suporte emocional/ psicológico, encaminhamento para outros serviços de assistência psicológica, social e jurídica do município e região [...] (Jéssica).

O reconhecimento da categoria enquanto profissional específico da DEAM compôs as reinvindicações das participantes, visto que grande parte das delegacias não conta com psicólogos em seu quadro efetivo, dificultando a prestação do serviço psicológico a este público alvo. Sabe-se que, na atualidade, no contexto brasileiro, o psicólogo não compõe o rol de profissionais da equipe mínima de uma DEAM. De acordo com a Norma técnica de padronização das delegacias especializadas de atendimento às mulheres - DEAMs (Brasil, 2010), a equipe da DEAM deve ser composta pelas funções de delegado (a), agente policial (escrivão/ã ou investigador/a), Apoio Administrativo e serviços gerais.

[...] não tenho dúvida que devemos lutar para que a legislação seja alterada e possamos ter psicólogos concursados atuando nesta área e podendo desenvolver políticas que contribuam com a prevenção da violência, redução da judicialização de conflitos familiares e fortalecimento da rede de apoio às mulheres em situação de violência [...] (Michele).

Deste modo, averiguou-se atuação profissional bastante diversificada, apontando que o papel do psicólogo não se limita somente ao espaço físico da delegacia, mas tangencia outras esferas da sociedade. Em concordância, Hanada, D'Oliveira e Schraiber (2010), verificaram através de pesquisa realizada com psicólogos que atuavam nas delegacias da mulher e serviços da rede de atendimento à mulher em contexto de violência o caráter heterogêneo das intervenções.

\section{Considerações Finais}

Esta pesquisa buscou caracterizar o trabalho do psicólogo na Delegacia Especializada de Atendimento à Mulher. Embora o estudo apresente 
limitações, dado o pequeno número de psicólogas encontradas atuando nesse contexto, foi possível problematizar questões que tangenciam essa prática profissional. Verificou-se que a atuação da Psicologia nas delegacias dá-se predominantemente pelo sexo feminino, com profissionais adultas de meia idade (46 a 55 anos). Essas apresentam pouca experiência profissional (entre 1 a 5 anos) e estão alocadas, especialmente, no Sudeste e Centro-Oeste.

Verificou-se que a inserção da Psicologia nas DEAMs tem ocorrido a partir de parcerias, já que no Brasil não há obrigatoriedade desse profissional no rol da equipe. Nessa direção, a universidade tem papel significativo, pois tem promovido essa inserção, embora, as questões de gênero e as políticas públicas de enfrentamento da violência ainda não sejam tônica nos cursos de graduação.

Observou-se que parcela das psicólogas já haviam vivenciado violência na vida íntima. Essa realidade suscita preocupação, pois se infere que questões pessoais quando pouco ou mal ressignificadas, podem comprometer o trabalho. Em contrapartida, a vivência de cunho pessoal pode permitir que o profissional tenha empatia pelo indivíduo, humanizando o atendimento prestado. Essa constatação leva a questionamentos, que apesar de não ter sido objeto desse estudo, podem ser problematizados em novas pesquisas: As psicólogas revivem seus dramas ao atenderem mulheres em situação de violência? Qual o rebatimento dessa situação no cotidiano de trabalho? Como se dá o autocuidado dos profissionais? Como manter a saúde psíquica frente a esse contexto?

No que diz respeito ao papel do psicólogo na DEAM, apontou-se como constituído por práticas diversificadas, desempenhando funções quanto a acolhimento psicológico, orientações e/ou informações à demanda atendida e encaminhamentos a outros serviços. A identidade do trabalho psicológico na DEAM ainda é difusa. Destaca-se a importância da formação profissional, bem como o desenvolvimento de normas técnicas e referências para a prática profissional, ampliando a responsabilidade do Conselho Federal de Psicologia (órgão regulador da profissão) frente a essa questão.

Ao trabalhar com a temática da violência, é de fundamental importância ressaltar a existência de documentos, convenções e leis que orientam a atuação profissional do psicólogo frente a esta complexa demanda. Entretanto, verificou-se que nenhum psicólogo os citou como sendo norteador de sua prática no contexto da DEAM, podendo indicar desconhecimento ou pouca apropriação quanto às estas legislações. Nessa direção, percebe-se que a atuação em delegacias da mulher é também marcada por inúmeras lacunas, dadas pela escassez de concursos públicos; pela carência da infraestrutura nos prédios que abrigam o serviço; pela insuficiência de diretrizes para a atuação do psicólogo, necessárias às orientações do "fazer profissional"; pela fragilidade do conhecimento teórico-metodológico para compreensão da temática e intervenção assertiva.

Destaca-se, por fim, a importância da realização de novas pesquisas referentes à violência contra a mulher e o papel do psicólogo nestas áreas de atuação, uma vez que tal tema possui relevância significativa e este estudo não esgota tal temática.

\section{Referências}

Adeodato, V. G., Carvalho, R. R., Siqueira, V. R., \& Souza, F. G. M. (2005). Qualidade de vida e depressão em mulheres vítimas de seus parceiros. Rev. Saúde Pública, 39(1), 108-113.

Balbueno, B. (2011). Investigação sobre atendimento psicossocial oferecido em delegacias de defesa da mulher. Psicólogo informação, 15(15), 69-82.

Brasil (1994). Organização dos Estados Americanos. Convenção interamericana para prevenir, punir e erradicar a violência contra a mulher, "Convenção de Belém do Pará", de 9 de junho 
de 1994. Recuperado de http://www.cidh.oas. org/basicos/portugues/m.Belem.do.Para.htm

Brasil (2005). Secretaria Especial de Políticas para Mulheres. Plano nacional de políticas para as mulheres. Recuperado de http://bvsms.saude. gov.br/bvs/publicacoes/pnpm_compacta.pdf

Brasil (2006). Presidência da República. Lei n. 11.340, de 7 de agosto de 2006. Recuperado de http://www.planalto.gov.br/ccivil_03/_ato20042006/2006/lei/111340.htm

Brasil (2010). Secretaria de Políticas para as Mulheres. Norma técnica de padronização das delegacias especializadas de atendimento às mulheres - DEAMs. Recuperado de http:// www.compromissoeatitude.org.br/wp-content/ uploads/2012/08/MJ-2010-Norma-Tecnica-Padronizacao-DEAMs.pdf

Brasil (2011). Secretaria de Políticas para as $\mathrm{Mu}-$ lheres. Pacto nacional pelo enfrentamento à violência contra as mulheres. Recuperado de http://spm.gov.br/publicacoes-teste/publicacoes/2011/pacto-nacional

Castro, A. E. F., \& Yamamoto, O. H. (1998). A psicologia como profissão feminina: apontamentos para estudo. Estudos de Psicologia, 3(1), 147-158.

CREPOP (2011). Documento de referência para atuação dos psicólogos em serviços de atenção à mulher em situação de violência (versão preliminar para consulta pública). Brasília: Conselho Federal de Psicologia; Centro de Referência Técnica em Psicologia e Políticas Públicas. Recuperado de http://www.crprj.org.br/documentos/2012-doc_mulheres.pdf

Faria, J. S., Souza, T. M. C. S. Questionário da pesquisa: "Caracterização do serviço de psicologia em delegacias especializadas de atendimento às mulheres (DEAM). 2013. Recuperado de https:// docs.google.com/forms/d/1gjzQkShB5FikZ7fEfBukW3VuquVHQoamh_VHscurBzY/ viewform

Gadoni-Costa, L. M., Zucatti, A. P. N., \& Dell'aglio, D. D. (2011). Violência contra a mulher: levan- tamento dos casos atendidos no setor de psicologia de uma delegacia para a mulher. Estudos de Psicologia, 28(2), 219-227.

Hanada, H., D’Oliveira, A. F. P. L., \& Schraiber, L. B. (2010). Os psicólogos na rede de assistência a mulheres em situação de violência. Revista Estudos Feministas, 18(1), 33-60.

Kiss, L. B., Schraiber, L. B., D’Oliveira, A. F. P. L. (2007). Possibilidades de uma rede intersetorial de atendimento a mulheres em situação de violência. Interface (Botucatu), 11(23), 485-501.

Lhullier, L. A. (Org). (2013). Quem é a Psicóloga brasileira? Mulher, Psicologia e Trabalho. Brasília: Conselho Federal de Psicologia.

Nardaz, M. G. (2009). A (in)visibilidade do gênero na psicologia acadêmica: onde os discursos fazem(se) política. (Tese de Doutorado, Universidade Federal do Rio Grande de Sul, Porto Alegre).

Nardaz, M. G., \& Koller, S. H. (2007). A marginalização dos estudos feministas e de gênero na psicologia acadêmica contemporânea. Psico, 38(3), 216-223.

Parada, M. (2009). Cartilha sobre violência contra a mulher. São Paulo: Ordem dos Advogados do Brasil. Seção de São Paulo.

Pasinato, W., \& Santos, C. M. (2008). Mapeamento das Delegacias da Mulher no Brasil. PAGU/ UNICAMP.

Porto, M. (2013). Mulheres em situação de violência e políticas públicas de atendimento psicológico: experiências e desafios da psicologia. (Tese de doutorado, Universidade de Brasília, Brasil).

Saffioti, H. I. B. (2001). Contribuições feministas para o estudo da violência de gênero. Cadernos Pagu, 16, 115-136.

Santana, A. M. (2010). Mulher mantenedora/homem chefe de família: uma questão de gênero e poder. GEPIADDE, 4(8), 71-87.

Santos, C. M., \& Izumino, W. P. (2005). Violência contra as mulheres e violência de gênero: notas sobre estudos femininos no Brasil. E.I.A.L., 16(1), 147-164. 
Villela, W. V., Vianna, L. A. C., Lima, L. F. P., Sala, D. C. P., Vieira, T. F., Vieira, M. L., \& Oliveira, E. M. (2011). Ambiguidades e contradições no atendimento de mulheres que sofrem violência. Saúde e Sociedade, 20(1), 113-123.

Recebido: março 16, 2015

Aprovado: dezembro 9, 2015 
